\title{
Laboratory Biogas Production from Kitchen Wastes and Applying an Adaptive Neuro Fuzzy Inference System as a Prediction Model
}

\author{
Kobra Salehi, Seyed Masoom Khazraee, Fatemeh Sadat Hoseini, and Farnoush Khosravanipour \\ Mostafazadeh
}

\begin{abstract}
Biogas, a clean and renewable energy could be very well substitute for conventional sources of energy. In this study kitchen wastes potential for biogas production was investigated. Batch digestion experiments were accomplished in the laboratory using $1 \mathrm{~L}$ capacity bottle reactors at ambient temperature, and the effect of some parameters such as solid waste concentration and sheep manure percentage on the gas production efficiency was investigated.

Also an adaptive nero-fuzzy interference system (ANFIS) was proposed as a prediction model to predict biogas production through kitchen wastes digester.

The selected experimental data were trained by a hybrid learning algorithm. The algorithm combines the forward pass and the backward pass. The developed model was validated and statistically analyzed using scatter diagram through actual and predicted data. The ANFIS predicted data demonstrated reasonable agreement with actual data.
\end{abstract}

Index Terms - Kitchen waste, sheep manure, batch digestion.

\section{INTRODUCTION}

Nowadays, a large proportion of the required world energy is being covered by fossil fuels and consumption of these non-renewable energy resources has been accelerated day by day [1]. Also combustion of fossil fuels releases carbon dioxide and various pollutants, such as sulfur and nitrogen oxides.

As a result, recently, the interest of using different renewable energy sources has been growing. One of the most important energy sources, which are also a solution for increasing the amount of waste, is biogas [1], [2].

Biogas, the gas generated via anaerobic digestion of biomass wastes (animal dung, plant residues, waste waters, municipal solid wastes, human and agro industrial wastes etc) by mixed population of microorganisms, is a renewable source of energy which is also environmentally friendly [2].

Due to the increasing importance of renewable energy

Manuscript received September 10, 2013; revised November 11, 2013.

Kobra Salehi is with the Department of Chemical Engineering, Darab Branch, Islamic Azad University, Darab, Iran (e-mail salehi.salehi@gmail.com).

Seyed Masoom Khazraee is with the Department of Chemical Engineering, Darab Branch, Islamic Azad University, Darab, Iran (Corresponding author e-mail: khazraee.masoom@gmail.com).

Fatemeh Sadat Hoseini is with the Young Researchers Club, Shiraz Branch, Islamic Azad University, Shiraz, Iran (e-mail: polytak2000@gmail.com).

Farnoush Khosravanipour Mostafazadeh is with the Environmental Research Centerin Petroleum and Petrochemical Industries, Shiraz University, Shiraz, Iran (e-mail: f.khosravanipour@gmail.com). development and need for sustainable management of organic waste, anaerobic digestion (AD) and biogas production technology interest has grown rapidly over the years[3], [4].

Biogas, depending on the feed materials, contains methane, carbon dioxide, nitrogen and typically hydrogen sulphide and other sulphur compounds, such as siloxanes and aromatic and halogenated compounds. The methane-rich biogas can be used for heat and power production and transport biofuel, while the use of carbon dioxide (biogas contain $25-45 \%$ carbon dioxide) can also be considered for various purposes [3]-[6].

Since kitchen waste contains high amounts of organic contents i.e. sugars, lipids, proteins, cellulose and other compounds which are degraded easily [7], in this paper authors tried to investigate biogas production from the most common kitchen wastes produced daily in their region. For this purpose, the daily food refuse from Islamic Azad University, Darab branch end kitchen was used. Also the effects of waste concentration and sheep manure percentage on biogas production using anaerobic digestion method were investigated.

For this purpose, the anaerobic digestion of kitchen waste was performed at original $\mathrm{pH}$ of slurry (initial $\mathrm{pH}$ 6.8-7.3), ambient temperature $\left(25-35^{\circ} \mathrm{C}\right)$ in a closed $1 \mathrm{~L}$ anaerobic digester.

\section{METHODOLOGY}

The waste generated in kitchen in the form of vegetable refuse, cooked and uncooked food wastes, extracted tea powder, milk and milk product wastes can all be processed in this experimental setup. Feed stocks were gathered from disposal of the waste generated in the University Kitchen. It was ensured that foreign materials like earth, sand, gravel, sawdust, soap, detergents, etc. did not enter the digester and all kinds of food wastes generated herein could be processed The wastes crushed into small pieces $\left(<0.1 \mathrm{~cm}^{3}\right)$ using blender. The samples were subjected to oven drying at $105^{\circ} \mathrm{C}$ for $24 \mathrm{~h}$ to estimate moisture content. Moisture contents of all samples were $<30 \%$.

Each sample was weighed and added to a known amount of water in an $1 \mathrm{~L}$ bottle. Some tests were performed in dark bottles some not. Also all tests were accomplished in ambient temperature.

The digester was stirred manually by shaking the bottles. The biogas generated was collected in a urine bag connected to a tube and the tube was placed in a displacer column. The 
biogas was measured by downward displacement of water.

\section{RESULT AND DISCUSSION}

\section{A. Experimental Data}

Based on our understanding of biogas process, biogas process depends on the proper segregation of the kitchen waste. Hence, firstly the fresh kitchen wastes were segregated and used for gas production tests. Solid waste concentrations of all samples were 7\%. As indicated in Fig. 1 gas generated from the segregated materials is negligible or no gas generation is observed.

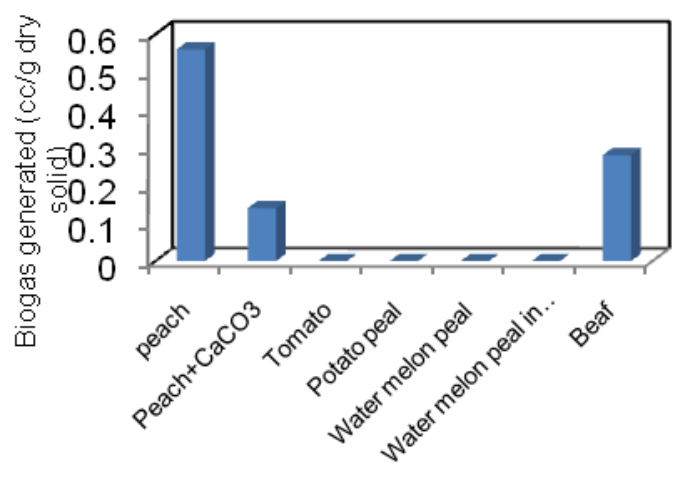

Type of solid waste

Fig. 1. Results of gas production tests from segregated and fresh kitchen wastes.

Also mixed and fresh kitchen waste was used to investigate gas production. The experimental results showed that no gas generation occurs in this case. Effect of $\mathrm{pH}$ on anaerobic digestion was investigated by adding $\mathrm{NaOH}(3 \%$ weight) to the initial slurry too. During two months no gas generation was occurred and it was observed that saponification has been occurred.

At the second stage, the one week remained mixed kitchen waste was crushed and the samples were poured in bottles with known amounts of water. Results of the experiments are indicated in Fig. 2.

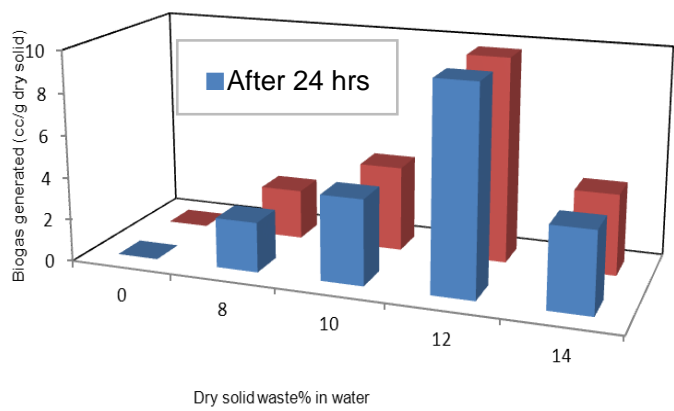

Fig. 2. Biogas production versus waste concentration.

In regards of various kinds of microorganisms activities as a main factor for anaerobic digestion which produces methane gas, results showed that the meth gens were so poor in quantity or had been killed due to the competition with other microorganisms in this case.

At the third stage, fresh and crushed solid waste was mixed with sheep manure at different percentages of waste and sheep manure and prepared samples were poured in water. Gas generation was occurred during 10 days (no more gas generated after this time duration). The properties of samples and the volume of total gas generated are shown in Table I.

TABLE I: OBTAINED RESUlTS OF GAS PRODUCTION FROM MiXED AND FRESH WASTE WITH SHEEP MANURE

\begin{tabular}{|c|c|c|c|c|}
\hline & $\begin{array}{c}\text { Experiment } \\
\text { NO. }\end{array}$ & $\begin{array}{c}\text { Waste\% in } \\
\text { water } \\
\text { (g dry } \\
\text { solid/100 cc } \\
\text { water) }\end{array}$ & $\begin{array}{c}\text { Sheep } \\
\text { manure } \\
\% \\
\text { in the } \\
\text { waste }\end{array}$ & $\begin{array}{c}\text { Biogas } \\
\text { generated } \\
\text { (cc/g dry } \\
\text { solid) }\end{array}$ \\
\hline \multirow{12}{*}{ Е } & 1 & 10 & 6.25 & 18.5 \\
\hline & 2 & 12 & 4.76 & 13.4 \\
\hline & 3 & 20 & 2.9 & 11.2 \\
\hline & 4 & 9 & 28 & 10.1 \\
\hline & 5 & 9.2 & 16.7 & 15.44 \\
\hline & 6 & 11.5 & 13.3 & 15.45 \\
\hline & 7 & 8 & 14.3 & 18.457 \\
\hline & 8 & 9.6 & 11.7 & 23.8 \\
\hline & 9 & 11 & 13 & 28.9 \\
\hline & 10 & 13.5 & 10 & 23.6 \\
\hline & 11 & 9.2 & 8.35 & 12.35 \\
\hline & 12 & 9 & 6.25 & 19.4 \\
\hline \multirow{5}{*}{$\stackrel{\overrightarrow{0}}{\stackrel{0}{H}}$} & 13 & 14 & 4.1 & 13.8 \\
\hline & 14 & 9.4 & 11 & 19.356 \\
\hline & 15 & 9 & 22 & 11.3 \\
\hline & 16 & 11 & 5 & 15.7 \\
\hline & 17 & 8 & 13 & 18.6 \\
\hline
\end{tabular}

\section{B. ANFIS Prediction Model}

In this study, an adaptive neuro-fuzzy interface system was applied to determine the viability of such a prediction model to this process.

The linear fuzzy rule in a Takagi and Sugeno's (TS) fuzzy model with 2 inputs has the form of (1):

$$
\begin{aligned}
& R^{m}:{ }_{\text {If }} X_{1} A_{i j} A_{1 j} X_{2} A_{2 j}, \\
& \qquad y^{m}=\left(\sum_{i=1}^{2} r_{i}^{m} X_{i}\right)+r_{0}^{m},
\end{aligned}
$$

$$
i=1,2 ; j=1,2 ; m=n^{5}
$$

where $R^{m}$ denotes the $m$ th fuzzy rule, $X_{i}$ the ith input parameter, $i$ the number of input parameters, $j$ the number of membership functions, $A_{i j}$ a fuzzy subset, $y^{m}$ the output for the mth fuzzy rule, and $r_{i}^{m}$ the ith parameters for the conclusion part of mth fuzzy rule. Fig. 3 depicts the ANFIS structure, which is a five feedforward connectionist network to realize a simplified TS fuzzy inference system [8].

The raw experimental data was used for model training and verification. Since the aim of this work was to investigate the biogas generated (cc/g) form dry solid under different experimental conditions, generated biogas was considered as an output variable, while the waste percentage and sheep manure percentage in the wastes were set as input variables. The number and type of membership functions and number of epochs should determine and the optimal combination of 
these was achieved by trial and error. The data sets were split into training and test sets randomly before training a fuzzy inference system. The test set is used when training should be terminated to prevent over fitting. The training set is used to tune a fuzzy model.

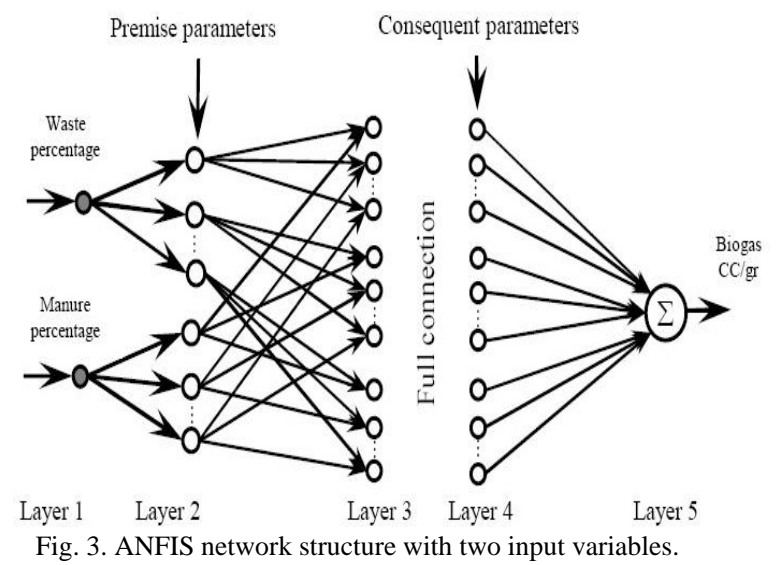

The best results were obtained from Gaussian mf type membership functions. The training of model was set up to 1000 epochs. In Fig. 4, the root mean square error (RMSE) for both training and experimental data are illustrated for each epoch and the error measure of the test and training data decreased for the initial epochs of the training data set. Therefore, the training was stopped when the test RMSE reached the minimum. Normally, the test error is used as a true measure of the model's performance. As a result, when the test error is minimal, the best model occurs.

$$
R M S E=\sqrt{\frac{1}{n} \sum_{i-1}^{n}\left(a_{i}-p_{i}\right)^{2}}
$$

where $a_{i}$ and $p_{i}$ are the actual and predicted values of instance $i$, respectively, and $n$ is the number of the training or testing samples.

In Fig. 5, represents the results of the best model using the scatter diagram. The figure compares predicted results from the ANFIS model with the experimental data for the training set. The correlation coefficient $\left(R^{2}\right)$ and adjusted correlation coefficient (adjusted $R^{2}$ ) of 0.9946 and 0.9927 respectively show that the predictions match quite well with the experimental data.

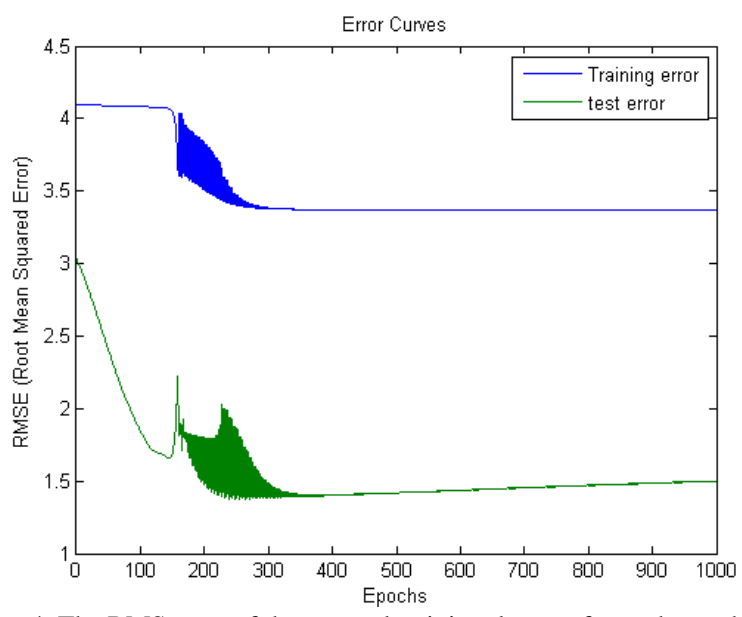

Fig. 4. The RMS error of the test and training data set for each epoch.

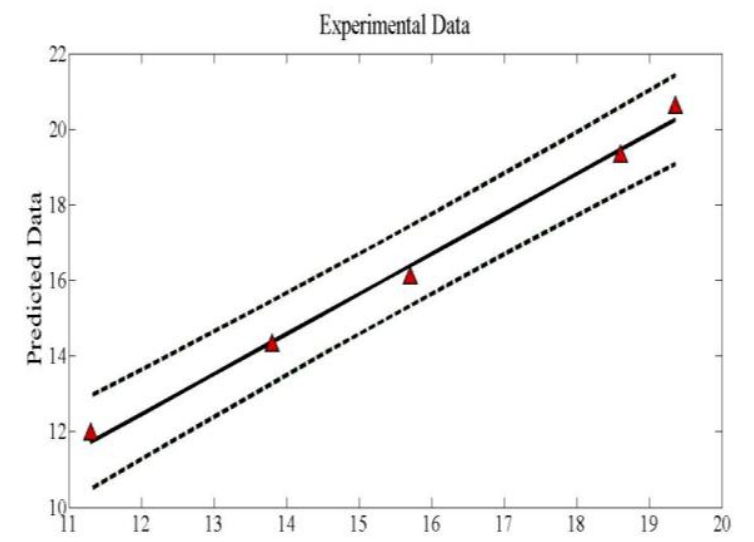

Fig. 5. Scatter diagrams showing the correlation between the predicted data using the ANFIS model and actual experimental data for the training sets. (_curve fitted through data, - - - 95\% prediction bounds, $\triangle$ Predicted data vs. Ex. Data, $R^{2}=0.9946$ and Adjusted $R^{2}=0.9927$ ).

\section{CONCLUSIONS AND RECOMMENDATIONS}

Slow degradation of solid waste is a disadvantage of anaerobic digestion leading to a retention time in conventional digesters of about 20 days. This fact implies significant space requirements and the construction of large equipment in this process. Through this study it has been observed that adding sheep manure to the solid waste can reduce the retention time, consequently the required space for digestion process is reduced considerably. Furthermore, regards to the experimental results it is obvious that there should be an optimum point for gas production due to the sheep manure percentage change through the bioreactor feed.

Results of an artificial neuro fuzzy inference system demonstrate well fitting between experimental test data and predicted data. It persuades authors to arrange a wide variety of experiments to optimize the best values for the laboratory set up and scale up in their future work.

\section{ACKNOWLEDGMENT}

Authors are grateful to Islamic Azad University, Darab Branch for providing financial support for carrying out this work.

\section{REFERENCES}

[1] G. Davila-Vazquez et al., "Fermentative biohydrogen production trends and perspectives II," Rev. Environ. Sci. Biotechnology, vol. 7 , pp. 27-45, June 2007.

[2] D. C. Stuckey, "Biogas: a global perspective," in Biogas Technology, Transfer and Diffusion, M. M. EL-Halwagi, Ed. Elsevier Applied Science, New York, U.S.A, 1984, pp. 18-44.

[3] Y. Singhal, S. K. Bansal, and R. Singh, "Evaluation of biogas production from solid waste using pretreatment method in anaerobic condition," International Journal of Emerging Sciences, vol. 2, no. 3 , pp. 405-414, September 2012.

[4] P. Milono, T. Lindajati, and S. Aman, "Biogas production from agricultural organic residues," The First ASEAN Seminar-Workshop on Biogas Technology, Working Group on Food Waste Materials, pp. 52-65, 1981 .

[5] M. Oslaj, B. Mursec, and P. Vindis, "Biogas production from maize hybrids," Biomass and Bbioenergy, vol. 34, pp. 1538-1545, May 2010

[6] H. Fredriksson et al., "Use of on-farm produced biofuels on organic farms-evaluation of energy balances and environmental loads for three possible fuels," Agricultural Systems, vol. 89, no. 1, pp. 184-203, July 2006.

[7] Q. Wang et al., "Effect of $\mathrm{pH}$ adjustment on preservation of kitchen waste used for producing lactic acid II," Water, Air, and Soil Pollution, vol. 144, pp. 405-418, April 2003. 
[8] J. S. R. Jang, C. T. Sun, and E. Mizutani, Neuro-Fuzzy and Soft Computing: A Computational Approach to Learning And Machine Intelligence, Prentice Hall, Upper Saddle River, NJ, USA, pp. 199-223, September 1997.

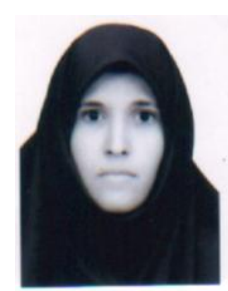

Kobra Salehi was born in Drab, Fars, Iran in 1972. She received her B.Sc. Degree in Chemical Engineering from Iran University of Science and Technology in 1996 and she received her M.Sc. and Ph.D. Degrees in Chemical Engineering from Shiraz University in 2001 and 2012 respectively. She has been as a lecture between 1997 and 2012, and now she is an assistant professor at Islamic Azad University, Darab Brunch.

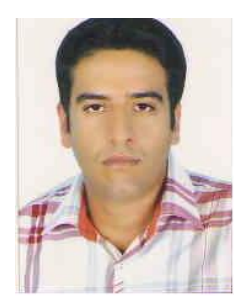

Seyed Masoom Khazraee was born in Drab, Fars, Iran in 1984. He received his B.Sc. Degree in Chemical Engineering from Tehran University in 2005 and he received his M.Sc. from Shiraz University in 2009. He has been a lecturer at Islamic Azad University, Darab Brunch between 2009 and 2012, and has been working as a researcher at Fars Engineering Research Centre (FERC) between 2009-2011

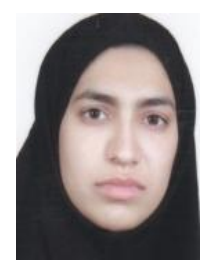

Fatemeh Sadat Hosseini was born in Drab, Fars, Iran in 1984. She received her B.Sc. Degree in Repolym Engineering from Islamic Azad University of Darab in 2005 and she received her M.Sc. from Islamic Azad University of Shiraz in 2012. She has been working as laboratory assistance at Islamic Azad University of Darab between 2007 and 2013, and now she is a lecturer at Islamic Azad University, Darab Brunch.

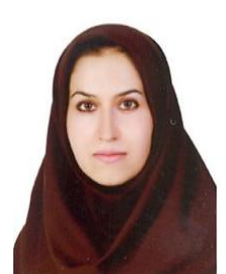

Farnoush Khosravanip Mostafazadeh received her B.Sc. Degree in Biology from Azad University of Jahrom in 2004. She is an instructor of water and waste water (chemistry and microbiology) lab at Chemical and Petroleum Engineering School in Shiraz University since 2007. She also cooperates with MEOR section in petroleum department, and Environmental and Biotechnology Lab in Shiraz University. 